\title{
Pancreatic Cancer and Platelets Crosstalk: A Potential Biomarker and Target
}

\section{Shaoshan Mai and Iwona Inkielewicz-Stepniak* \\ Department of Pharmaceutical Pathophysiology, Faculty of Pharmacy, Medical University of Gdańsk, Gdańsk, Poland}

Platelets have been recognized as key players in hemostasis, thrombosis, and cancer. Preclinical and clinical researches evidenced that tumorigenesis and metastasis can be promoted by platelets through a wide variety of crosstalk between cancer cells and platelets. Pancreatic cancer is a devastating disease with high morbidity and mortality worldwide. Although the relationship between pancreatic cancer and platelets in clinical diagnosis is described, the interplay between pancreatic cancer and platelets, the underlying pathological mechanism and pathways remain a matter of intensive study. This review summaries recent researches in connections between platelets and pancreatic cancer. The existing data showed different underlying mechanisms were involved in their complex crosstalk. Typically, pancreatic tumor accelerates platelet aggregation which forms thrombosis. Furthermore, extracellular vesicles released by platelets promote communication in a neoplastic microenvironment and illustrate how these interactions drive disease progression. We also discuss the advantages of novel model organoids in pancreatic cancer research. A more in-depth understanding of tumor and platelets crosstalk which is based on organoids and translational therapies may provide potential diagnostic and therapeutic strategies for pancreatic cancer progression.

Keywords: pancreatic cancer, platelets, TCIPA, platelet-derived factors, platelet extracellular vesicles, angiogenesis, organoids, biomarker

\section{INTRODUCTION}

Significant interaction of tumor cells with platelets is a longstanding concept. Preclinical and clinical studies showed that tumorigenesis, progression, angiogenesis, and metastasis can be promoted by platelets through a wide variety of crosstalk between platelets and cancer cells. Correlations between high platelet counts and poor prognosis are often described for lung, colon, breast, kidney, ovarian, and pancreatic cancers. Platelet-based biomarkers as liquid biopsy for cancer patients will be a potential platform for improving diagnosis. High risk of venous thrombosis and metastasis have close interrelations with platelets in patients with pancreatic cancer (Sylman et al., 2017). However, studies focused on crosstalk between pancreatic cancer and platelets in different ways are not fully explored compared with other tumors. For example, platelet $\alpha$-granules contain many different bioactive factors such as vascular endothelial growth factor (VEGF), platelet-derived growth factor (PDGF), epidermal growth factor (EGF), endostatin, angiostatin, platelet factor-4 (PF4), or thrombospondin, the exact mechanisms of granule release and whether they can be selectively manipulated in pancreatic cancer requires more study. In addition, platelet derived-microparticles and RNA profile alteration are prospective directions for pancreatic cancer 
diagnosis and treatment (Thaler et al., 2012; Best et al., 2015). At the same time, multiple drugs have been developed to interfere with cancer growth or metastasis by inhibiting the functions of platelets. These drugs are in pre-clinical development or already in clinical treatment, which target platelet receptors, inhibit platelet granule release, or interfere with platelet-related enzymes (Dovizio et al., 2013; Elwood et al., 2016; Sun et al., 2019). In this review, we summarize recent discoveries in the field of pancreatic cancer and platelets. Compared with other cancer research with platelets, we discuss the potential exploration in pancreatic cancer. Moreover, we propose a suitable research model for pancreatic cancer and platelets investigation, which provides an insight for further study.

\section{OVERVIEW OF PANCREATIC CANCER}

Pancreatic cancer remains one of the most lethal neoplasms worldwide. There are three histological classifications of pancreatic cancer. The pancreatic ductal adenocarcinoma (PDAC) comes from the duct cells of exocrine tissue, which represents the most common ( $>90 \%$ ) type. There is one subtype that exhibits both characteristics of adenocarcinoma and squamous carcinoma. It is adenosquamous carcinomas concerning $1-4 \%$ of the exocrine malignancies. The other types are acinar and neuroendocrine tumors. According to Globocan estimates, there were more than 495,773 new patients diagnosed and about 466,000 deaths of pancreatic cancer in 2020 .

From precursor to invasive cancer, there are three welldefined PDAC precursor lesions: Intraductal papillary mucinous neoplasms (IPMNs), mucinous cystic neoplasms (MCNs), and pancreatic intraepithelial neoplasm (PanIN), the latter being the most frequent precursor lesion which further divided into PanIN1, 2, and 3 (Hezel et al., 2006; Hruban et al., 2007).

Pancreatic cancer often does not cause symptoms in the early stages, which makes it difficult to diagnose. Common symptoms include tummy pain or back pain, weight loss, indigestion, losing appetite, diarrhea, constipation, jaundice, blood clots, and fatigue. These symptoms can have many causes, and are unlikely to be pancreatic cancer. Thus, different kinds of tests are essential for diagnosis. The tests used to diagnose pancreatic cancer include 1. Blood test, such as blood cell count, liver and kidney function, or tumor markers (such as CA19-9, CEA, B72.3); 2. Ultrasound scan of the abdomen. 3. Computerized tomography (CT) scan or Positron emission tomography (PET-CT) scan. 4. Magnetic resonance imaging (MRI) scan or Magnetic resonance cholangio-pancreatography (MRCP). 5. Endoscopic ultrasound scan (EUS) or with/without Biopsy. 6. Endoscopic retrograde cholangio-pancreatography (ERCP) is usually used if the bile duct is blocked. 7. Laparoscopy. According to these tests, the information about tumor size, burden, and local vessel involvement can be achieved that necessary to determine the TNM (Tumor, Nodes, Metastases) stage (van Roessel et al., 2018).

Currently, the treatments for pancreatic cancer are chemotherapy, surgery, radiation therapy, targeted therapy, and immunotherapy. Only about $20 \%$ of people diagnosed with pancreatic cancer are eligible for surgical treatment because most are found after the disease has already spread. The kinds of surgery that are performed depend on the purpose of the surgery. For example, the Whipple procedure, which is carried on if the tumor is located only in the head of the pancreas. However, a Distal pancreatectomy is commonly done if the cancer is in the tail of the pancreas. Usually, surgery will combine with systemic therapy or/and radiation therapy. Adjuvant therapy is given after surgery. Sometimes, a few treatments are used to shrink a tumor before surgery, this is called neoadjuvant therapy or pre-operative therapy. Radiation therapy is performed by highenergy x-rays or other particles to destroy cancer cells such as traditional radiation therapy, stereotactic body radiation (SBRT) or cyberknife, proton beam therapy. Typically, chemotherapy will combine with radiation therapy at the same time, which is named radiosensitization. Chemotherapy is the main type of systemic therapy and includes an intravenous tube placed into a vein by a needle or orally. One type or a combination of different medications are used in patients. Currently, the drugs approved for pancreatic cancer are: Fluorouracil (5-FU), Capecitabin, Gemcitabine, Erlotinib, Leucovorin, Irinotecan, Nab-paclitaxel, Nanoliposomal irinotecan, and Oxaliplatin. In addition, there are some targeted treatments that focus on the specific genes of the cancer, proteins, or the tissue environment. For example, Erlotinib blocks epidermal growth factor receptor (EGFR), Olaparib influences a hereditary BRCA mutation, and Larotrectinib can be used for NTRK fusion (Wang et al., 2015; Filippi et al., 2021; Tutt et al., 2021). Moreover, Immunotherapy has become popular in recent years. Immune checkpoint inhibitors are an option for treating pancreatic cancer with high microsatellite instability (MSI-H), which include anti-PD-1 antibodies such as pembrolizumab (Diaz et al., 2017). Different treatment options are dependent on the stage of the tumor. For instance, resected patients' chemotherapy will be gemcitabine or 5-FU based treatment, however, metastatic cancer will use Gemcitabine plus Nab-paclitaxel or a combination of 5-FU, Leucovorin, Irinotecan, and Oxaliplatin called FOLFIRINOX. Nevertheless, surgery is not the main method of treatment. The appropriate therapeutics are referenced to European Society for Medical Oncology (ESMO) guideline (Ducreux et al., 2015).

\section{PLATELET FUNCTION}

Platelets derive from megakaryocytes, which exist in circulation for 5-7 days. The size is approximately 2-4 $\mu \mathrm{m}$ and their volume is about $7 \mu \mathrm{m}^{3}$. A normal number of platelets ranges between 150,000 and 450,000 per microliter of blood. They are removed from blood vessels by macrophages and neutrophils and, leave the body by the spleen.

The primary role of platelets is to maintain hemostasis, by the formation of a "platelet clot" (Tomaiuolo et al., 2017). Following vascular damage, initial platelet tethering is mediated by the interaction between the GPIb $\alpha$ in the platelet receptor GPIb-IX$\mathrm{V}$ and A1 domain of Von Willebrand factor (vWF) deposited in the subendothelial matrix of the injured vessel wall. After platelet tethering, GPVI and $\alpha \mathrm{II} \beta 1$ receptors promote platelet adhesion 
and activation (Ruggeri and Jackson, 2013; Welsh et al., 2014). GPVI has a low affinity for collagen. The $\alpha \mathrm{II} \beta 1$ maintains stable adhesion to collagen and reinforces GPVI-collagen interaction. Subsequent stable adhesion occurs via binding of fibronectin, $\alpha \operatorname{IIb} \beta 3$, laminin, and vWF. In addition, platelet adhesion will form positive feedback to initiate circulating platelets activation. The final step is platelet aggregation by the binding of fibrinogen or vWF to $\alpha \operatorname{IIb} \beta 3$.

Apart from hemostasis and thrombosis, platelets also play an important role in immune activities. Platelets are able to recognize and interact with microbial pathogens including bacteria, viruses, and parasites. Platelet bounding shifts fee L. monocytogenes from "fast" clearance into CRIg-dependent "slow" clearance pathways (Broadley et al., 2016). In addition, different platelet receptors have various effects on cancer progression (Supplementary Table 1). Platelets express tolllike receptors from TLR1 to TLR9 which identify molecular motifs called pathogen-associated molecular patterns (PAMPs) (Cognasse et al., 2015). Interaction between platelets and leukocytes, monocytes, and granulocytes are evidenced, which through different receptor-ligands such as P-Selectin, PSGL-1. Platelets are involved in angiogenesis. Their activation facilitates release, eliciting potent angiogenic responses. Moreover, the release of platelet-derived phospholipids and microparticles are as synergistic regulators of angiogenesis (Walsh et al., 2015). However, tumor growth can be aggravated by uncontrolled angiogenesis. Luminal breast cancer cells secret cytokines absorbed by platelets, which help vessel formation (Kuznetsov et al., 2012). Recently, it has been established that platelets play a crucial role in cancer cell metastasis. Platelets make contact with tumors by direct surface interactions, such as surface receptors and glycoproteins, indirect platelet growth factors, such as VEDF, TGF- $\beta$, and microparticles (MP) (Goubran et al., 2014). Plateletderived signals, for example, CXCL5 and CXCL7 are required for the rapid recruitment of granulocytes to tumor cells to form early metastatic niches (Labelle et al., 2014). Colorectal cancer cell interaction with platelets produces chimeric extracellular vesicles like three types of microparticles that promote metastasis through EMT and endothelial activation (Plantureux et al., 2020). Activated platelets P-selectin interact with circulating tumor cell P-selectin ligands, which form aggregation and prevent shear force-induced tumor membrane damage (Coupland and Parish, 2014; Egan et al., 2014). Accordingly, platelets and tumor cell interaction promote tumor cells extravasation (Haemmerle et al., 2018; Marcolino et al., 2020).

\section{CROSSTALK BETWEEN PANCREATIC CANCER AND PLATELETS}

\section{Pancreatic Cancer Influences Platelets Tumor Cell-Induced Platelet Aggregation and Thrombopoiesis}

Tumor cell-induced platelet aggregation (TCIPA) is not a new concept, which can be traced back to the late nineteenth century. For pancreatic cancer cells, it was evidenced by six human cell lines, which can induce platelet aggregation via activation of thrombin (Heinmöller et al., 1995). Several molecular pathways are involved in pancreatic TCIPA. Activated phospholipase A2 enzymes release arachidonic acid (AA) which is a precursor of thromboxane A2 (TXA2). Cyclooxygenase 1 (COX-1) catalyzes the transformation of AA into TAX2, which is important for platelet aggregation. TAX2 can activate the thromboxane receptor-induced changes of platelet shape, activation of integrins, and degranulation. Moreover, the expression of COX-2 is reported as increased in tissues of pancreatic cancer (Ding et al., 2003; Sangkuhl et al., 2011). P-selectin and tissue factor (TF) accumulation are associated with platelet activation and platelet-rich thrombus (Wang et al., 2012; Mezouar et al., 2015; Hisada et al., 2017). The increased von Willebrand Factor (VWF), a large polymeric glycoprotein, is involved in the adhesion and aggregation of platelets. Cancer patients are associated with a higher risk of venous thrombosis. Especially, high VWF levels were observed in pancreatic, lung, brain, stomach, and colorectal cancer patients (Obermeier et al., 2019). Podoplanin on the surface of cancer cells induces platelet aggregation. Pancreatic cancer-associated fibroblasts (CAF) reportedly express podoplanin (Takemoto et al., 2017; Suzuki-Inoue, 2019). In addition, a recent study showed pancreatic cancer (Paca) cells can stimulate the rapid release of neutrophil extracellular traps (NETs) and promote thrombus formation (Abdol Razak et al., 2017).

\section{Changes of Phenotype}

In patients diagnosed with pancreatic cancer at the head of the pancreas, platelet count and concentration of vascular endothelial growth factor (VEGF) released from platelets were significantly increased (Sabrkhany et al., 2017). Mean platelet volume (MPV) is changed in different stages of pancreatic cancer (PC). MPV was elevated in PC patients with synchronous liver metastases and stage III-IV (Yin et al., 2018). However, MPV was decreased in resectable PC patients with poor prognoses (Yagyu et al., 2021). Best et al. (2015) evidenced mRNA profiles of tumor-educated blood platelets (TEPs) were different between KRAS mutant pancreatic cancer and KARS wild-type. TEPs RSL24D1 mRNA was negatively related to early pancreatic cancer compared to healthy controls (Xue et al., 2018). Moreover, the platelet proteome of patients with head of pancreas cancer (stage I-II) is significantly different from that of healthy individuals of equivalent sex and age (Sabrkhany et al., 2017, 2018).

\section{Extracellular Vesicles Release and Alteration}

Extracellular vesicles (EVs) are a means that facilitate the exchange of a broad array of molecules between adjacent or distant cells. Platelet EV cargo includes lipids, protein, nucleic acids, and organelles, which can enter lymph, bone marrow, and synovial fluid. EVs are classified into exosomes (30-150 $\mathrm{nm})$, microvesicles-also referred as microparticles or ectosomes-(100-1,000 nm), and apoptotic bodies (1,000$3000 \mathrm{~nm}$ ) (Ferreira et al., 2020). Platelet-derived extracellular vesicles (PDEVs) are the most abundant type of EVs in the circulation. Microparticle (MP) refers to particles released from the surface of cells, especially in the field of platelet research 
(Supplementary Table 2). Patients with pancreatic cancer had significantly increased levels of MP-associated TF activity compare with healthy controls (Tesselaar et al., 2007; Tilley et al., 2008). MP-TF activity had a strong association with mortality in pancreatic cancer, which could be a marker for aggressive cancer phenotype (Thaler et al., 2012). In addition, circulating microvesicles (MVs)-associated thrombin generation is different between patients and healthy control (Hellum et al., 2017).

\section{RNA Profiles Alteration}

Platelet messenger RNA (mRNA) profile is currently emerging as a new potential biomarker in cancer diagnosis. A study demonstrated platelets isolated from glioma or prostate cancer patients contained the cancer-associated mRNA transfer EGFRvIII and PCA3 (Nilsson et al., 2011). Recent studies highlighted pancreatic tumors can alter platelet RNA profiles (Best et al., 2015). Platelets from cancer patients contained tumor-associated RNA biomarkers, indeed, mRNA sequencing of tumor-educated platelets can identify pancreatic cancer patients with $96 \%$ accuracy.

\section{Platelets Are Involved in Pancreatic Tumor Progression \\ Platelets and Platelet-Derived Factors Are Biomarkers for Diagnosis and Prodiagnosis}

MPV is associated with the overall survival of pancreatic cancer patients (Yin et al., 2018). Particularly, large platelet size is associated with poor outcomes in patients with metastatic pancreatic cancer (Lembeck et al., 2019). However, reduced MPV levels predict shorter survival in patients after surgery (Yin et al., 2020). There is a novel scoring system based on hemostatic parameters that showed platelet count was an independent prognostic factor in advanced pancreatic cancer (Zhang et al., 2019). In many studies, CA19-9 decrease during treatment has been related to longer survival of pancreatic cancer. Moreover, the correlation of CA19-9 decreases; overall survival was stronger in advanced pancreatic cancer with fewer platelets (Chen et al., 2019). The preoperative platelet to lymphocyte ratio (PLR) was reported to be a significant independent prognostic factor in patients (Song et al., 2017). In addition, the increased PLR is also related to a poor longterm prognosis in resected pancreatic cancer (Yu et al., 2018; Negoi et al., 2019). Combining PLR and CA19-9 values could allow earlier diagnosis of pancreatic cancer patients with type 2 diabetic patients (Qin et al., 2019). Preoperative plateletto-albumin ratio (PAR) was reported as a novel significant independent prognostic index for disease-free survival (DFS) and overall survival (OS) in patients after pancreatic resection (Shirai et al., 2017). Moreover, platelet receptors and platelet-derived factors are also involved in cancer progression (Supplementary Table 1). The platelet-derived growth factor (PDGF) signaling pathway plays an important role in the progression of pancreatic cancer. Duan et al. (2018) analyzed three published genomewide association study datasets to observe genetic variants in the PDGF subunit $B$ gene associated with pancreatic cancer risk in European populations. High levels of circulating PDGF-AA serve as a predictor of poor cancer-specific survival, whereas high levels of PDGF-BB are associated with a favorable prognosis (Rahbari et al., 2011; Kahlert et al., 2014). In addition, PDGFR beta (PDGFR $\beta$ ) is more frequently expressed in primary endocrine pancreatic tumors (EPTs) and metastases as compared to normal endocrine pancreatic tissue (Fjällskog et al., 2007). PDGFR $\beta$ is a marker of activated pancreatic stellate cells (PSCs) which play a vital role in desmoplasia. Higher expression of PDGFR $\beta$ matched shorter prognosis as well as lymphatic invasion and lymph node metastasis (Yuzawa et al., 2012).

\section{Platelets Accelerate Proliferation and Angiogenesis}

Recent researches evidence that platelets have a direct effect on tumor cell proliferation. PANC-1 cancer cell proliferation was potentiated by human platelets in a manner dependent on the upregulation and activation of the oncoprotein c-MYC (Mitrugno et al., 2017). Platelet-derived growth factor (PDGF) is an important cytokine in pro-proliferative and invasion signaling, which plays a key role in the regulation of interactions between pancreatic cancer cells and adjacent stroma (Haqq et al., 2016). Moreover, dual-specificity phosphatase 28 (DUSP28) regulates chemo-resistance and migration in pancreatic cancers. PDGF-AA was evidenced in a public microarray database and in vitro assay, which is a critical role in pancreatic cancer malignancy. In addition, DUSP28 and PDGF-AA formed an acquired autonomous autocrinesignaling pathway. Targeting DUSP28 inhibited the tumor growth and migratory features through the blockade of PDGFAA expression and intracellular signaling (Lee et al., 2017). Mucin 1 (MUC1), a transmembrane mucin glycoprotein, regulates PDGFA expression and secretion in pancreatic cancer cells, accordingly, influences the proliferation of pancreatic tumors (Sahraei et al., 2012). There are some treatments for targeting PDGF to decrease the proliferation of pancreatic cancer cells (Inoue et al., 2017; Salem et al., 2020). PDGF-BB mediates pancreatic cancer growth via regulation of the Hippo/Yesassociated protein signaling pathway (Li et al., 2021). NF-кB is the downstream stage of the AA pathway. NF- $\mathrm{BB}$ and activator protein 1(AP-1) can bind to COX-2, lipoxygenases (LOXs), and phospholipase A2 (PLA2), which play a pro-tumorigenic role in pancreatic cancer (Gong et al., 2014; Matejcic et al., 2018). COX-2 is only expressed in pancreatic islets and has no expression in normal exocrine pancreatic tissues. Numerous clinical studies reported that mRNA and protein expression of COX-2 are up-regulated in pancreatic cancer. The use of aspirin, the major pharmacological inhibitor of COXs, was negatively related to the incidence risk of pancreatic cancer (Sun et al., 2019). Moreover, low-dose aspirin (81-162 mg orally daily) is relatively selective for COX-1 inhibition, interaction with circling tumor cells, and platelet aggregation. However, two large cohort studies reported regular aspirin or non-aspirin NSAID use was not associated with future risk of pancreatic cancer. There is only a possible reduction in patients of pancreatic cancer with diabetes (Khalaf et al., 2018). Pancreatic cancer cells express the purinergic receptor $\mathrm{P} 2 \mathrm{Y} 12$, that is an $\mathrm{ADP}$ receptor found mainly on platelets. Ticagrelor, a P2Y12 inhibitor, decreases the survival signals initiated in cancer cells by platelet-derived ADP and ATP (Elaskalani et al., 2017). Arachidonate 12-lipoxygenase 
(ALOX12) and 12-hydroxyeicosatetraenoic acid contribute to stromal aging-induced progression of pancreatic cancer (Sarsour et al., 2020). 5-lipoxygenases (5-LOX) were found overexpressed in the tissues of pancreatic cancer, the inhibition of 5-LOX induces apoptosis in pancreatic cancer cells (Zhou et al., 2015). In addition, P-selectin deficiency and soluble P-selectin abolish platelet deposition within tumors, decreasing the secretion of vascular endothelial growth factor and angiogenesis, thereby suppressing tumor growth (Qi et al., 2015). Rivipansel inhibits selectins and decreases the recruitment of plasma cells in multiple myeloma (Azab et al., 2012). Crizanlizumab, a selective blocking antibody of P-selectin, also is indicated as a potential treatment option for patients with pancreatic cancer in the future. Selected clinical trials of glycobiology-targeted therapeutics for pancreatic cancer are in Phase I, for example MVT-5873 and MVT10775 (Smith and Bertozzi, 2021). The first study for platelets involved in tumor angiogenesis is by Pinedo et al. (1998) They proposed platelets as a rich source of stimulators and inhibitors of angiogenesis and their interaction with the endothelium. Starlinger et al. (2011) compared different methods to get circulating platelet-stored angiogenesis factors in pancreatic cancer patients, and a significant increase of thrombospondin 1 (TSP-1) and platelet factor 4 (PF-4) were determined. The overexpression of VEGF and platelet-derived endothelial cell growth factor (PD-ECGF) protein significantly correlated with high microvessel density (MVD) in patient tissues of pancreatic cancer (Fujimoto et al., 1998). VEGF is a chemotactic vascular permeability factor stored in $\alpha$-granules and released from activated platelets. The study evidenced that VEGF expression correlated significantly with increased intratumoral microvessel density (IMD), which are important regulators of pancreatic tumor angiogenesis and predictive of benefit from adjuvant therapy (Khorana et al., 2005). Platelet factor 4 (PF-4) inhibits angiogenesis in vivo and in vitro (Maione et al., 1990). PF4 modulates fibroblast grow factor 2 (FGF-2) activity (Perollet et al., 1998). However, a study reported that FGF-1 and FGF-2 treatment led to the induction of phosphorylation of $\mathrm{E}$-cadherin and $\beta$-catenin on tyrosine residues, resulting in angiogenesis in pancreatic cancer cells (El-Hariry et al., 2001). Accordingly, FGFR also plays a key role in tumor angiogenesis, downregulations of FGFR-2 led to decreased phosphorylation of ERK and VEGF-A in PDAC cells after FGF-2 stimulation (Compagni et al., 2000; Kang et al., 2019). Platelets are the sole source of EGF in circulation, however, inhibition of EGFR tyrosine kinase activity suppresses pancreatic tumor angiogenesis (Bruns et al., 2000). Interleukin-8 (IL-8) is a chemokine related to PF-4, which activates G-protein coupled receptors as a proangiogenic factor (Le et al., 2000). Platelets contain 40-100 times more TGF- $\beta$ than other non-neoplastic cells (Assoian et al., 1983). Although TGF- $\beta$ is a pro-angiogenic factor in many cancers, the role in PDAC is controversial. TGF- $\beta$ interferes with a soluble TRRII, which suppresses pancreatic cancer angiogenesis (Rowland-Goldsmith et al., 2002). Contrarily, other studies evidenced TGF $\beta 1$ is overexpressed in PDAC, and it induces plasminogen activator inhibitor-1(PAI-1) expression in pancreatic cancer cells, promoting angiogenesis in vivo (Andreasen et al., 2000). TGF- $\beta$ can promote stromal activation, which induces angiogenesis and attenuates a productive antitumor immune reaction (Hinz et al., 2007; Kano et al., 2007). Similarly, because pancreatic cancer has a highly hypoxic microenvironment, in which hypoxia-inducible factor- $1 \alpha$ (HIF$1 \alpha)$ is activated. HIF-dependent pathways subsequently activate HGF/c-MET signaling pathway in pancreatic tumor cells, and induce angiogenesis (Kitajima et al., 2008). HDF can also be anti-angiogenic due to alternative splicing of the $\alpha$-chain (Date et al., 1998). Platelets can induce several matrix metalloproteinase (MMPs) in platelet-tumor cell interactions. Integrin engagement leads to the secretion of MMP-2, MMP-9 and surface expression of MT1-MMP. MMP-9 is essential to angiogenesis in pancreatic cancer mice model (Nakamura et al., 2007). Expression of MMP2 and MMP-9 mRNA are associated with microvessel density in pancreatic cancer patients (Xiang et al., 2017). Plateletderived microparticles (PMP) can enhance tumor growth by the release of potent growth factors in the tumor micro-environment (Goubran et al., 2015).

\section{Platelets Facilitate Metastasis}

That platelets promote tumor metastasis is not a new idea. Activation of platelets and the TF-thrombin-PAR-1 pathway are reported to promote metastasis of PDAC cells (Yang et al., 2019). The activation of platelets increases lysophosphatidic acid (LPA) release from platelets, LPA in turn enhanced tumor cell invasiveness and cell migration (Yoshikawa et al., 2013). In addition, vWF-platelet interactions also promote a number of metastases (Patmore et al., 2020). Tumor cellderived MMPs can elicit platelet activation, accordingly, plateletactivating factors can induce an increased MMP expression, and inhibition of MMP reduces both growth of pancreatic cancer metastases and the death rate (Jimenez et al., 2000). High TGF- $\beta$ induced expression in PDAC patients is associated with pancreatic cancer cell migration (Costanza et al., 2019). Moreover, TGF- $\beta$ has a role as a suppressor of stromal promotion or through alterations in pancreatic stellate cell MMP profiles with subsequent inhibition of pancreatic cancer cell migration (Tjomsland et al., 2016). Platelets secrete a mountain of growth factors and chemokines, such as VEGF, PDGF, CXCL5, to help establish metastatic foci, neovessel formation, and metastasis. In addition, inhibition of platelets activation prevents the P-selectin and integrin-dependent accumulation of pancreatic cancer cell microparticles and reduces metastasis (Mezouar et al., 2015). ADAM9 contributes to vascular invasion and is involved in metastasis (Oria et al., 2019). Epithelial-mesenchymal transition (EMT), a transient and reversible process, promotes cell motility, invasion, and dissemination of cancer cells out of the tumor microenvironment. Extravasated platelet aggregation is associated with the first step in the formation of EMT. Primary tumor cells surrounded by platelets exhibited characteristics of EMT in pancreatic cancer (Miyashita et al., 2015).

\section{Platelets Improve Pancreatic Cancer Chemotherapy Resistance}

A few studies have shown platelets can influence the efficacy of chemotherapy. Platelets increase the resistance of colon 
and ovarian cancer to 5-fluorouracil and paclitaxel (RadziwonBalicka et al., 2012). Platelet factors hinder the cytotoxicity of sorafenib and regorafenib in hepatocellular carcinoma by increasing the phosphorylation of ERK and p38 (D'Alessandro et al., 2014). Elaskalani et al. (2017) evidenced that plateletderived ADP and ATP promote pancreatic cancer cell survival
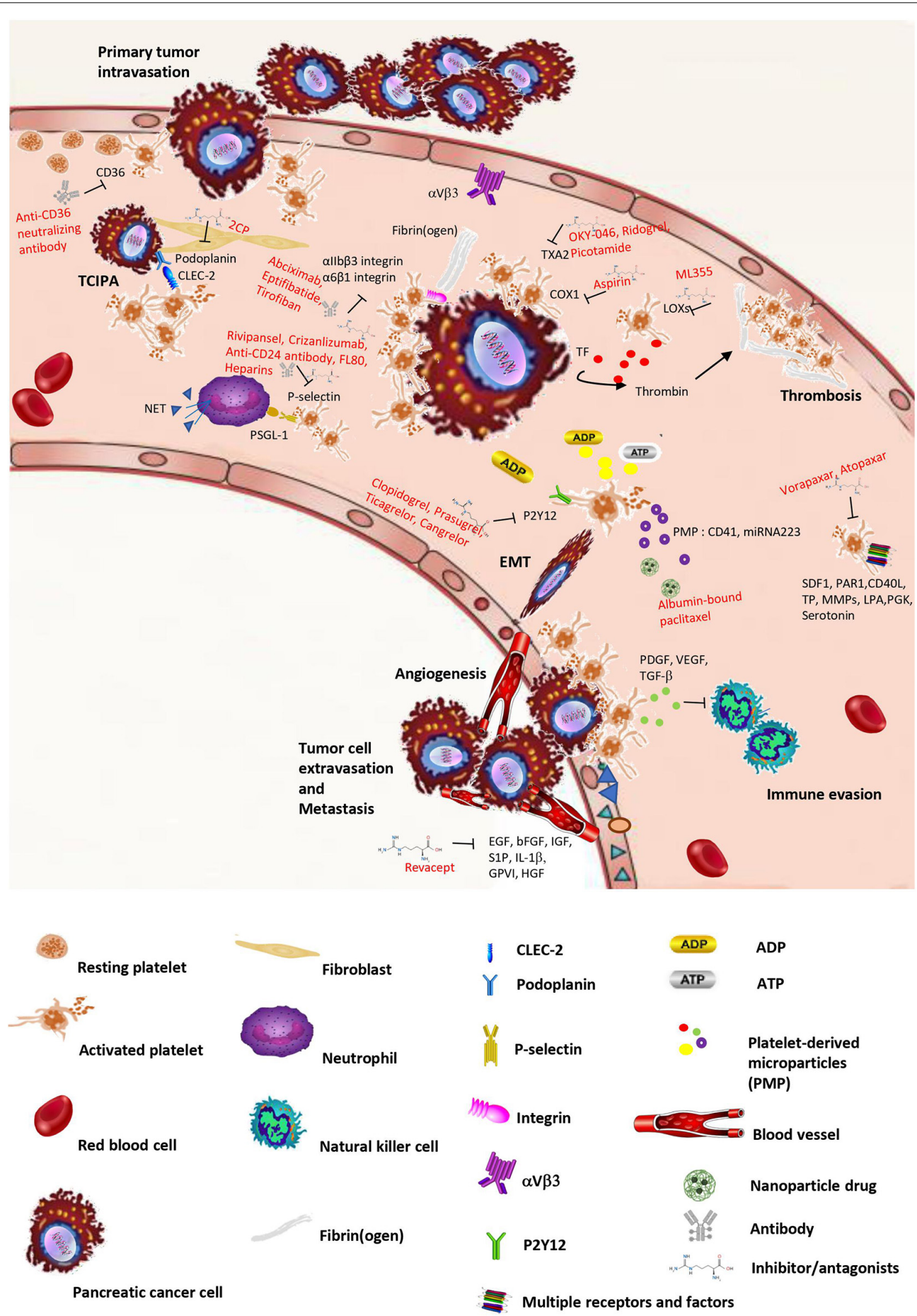

FIGURE 1 | Schematic overview of crosstalk between platelets and pancreatic cancer. Pancreatic cancer can stimulate platelet activation and aggregation (TCIPA), change platelet shapes, and increase platelets' release of microparticles with loading factors. However, platelet activation releases different kinds of factors, small molecules, and microparticles, which facilitate tumor growth, invasion, and metastasis. In the bloodstream, the tumor cell is surrounded by platelets that protect the encircled tumor cell from immune attack. In addition, platelets increase the properties of cancer cell adhesion and extravasation, thereby supporting cancer cell transmigration and metastasis. The intervention or inhibition of potential drugs in crosstalk between cancer and platelets are shown in the process. 
and gemcitabine resistance. Ticagrelor, an inhibitor of ADPP2Y12 axis, enhances chemotherapeutic efficacy in pancreatic cancer cells by targeting the Novel P2Y12-AKT pathway (Elaskalani et al., 2020). In addition, platelets also drive EMT to promote chemotherapy resistance. $\beta 1$ integrin-dependent interaction within the tumor microenvironment may alter tumor response to chemotherapy.

\section{CONCLUSION AND POTENTIAL DIRECTION}

This review highlights evidence for crosstalk between pancreatic cancer and platelets. Cancer influences platelets in different ways, such as TCIPA, thrombopoiesis, phenotype, and extracellular vesicles release. However, platelets are not only bystander cells in circulation, but also play a vital role in primary tumor growth and in the whole metastatic process (Figure 1). Although these relationships between platelets and cancer are reported in various kinds of tumors, they are still not full evidenced in pancreatic cancer. Platelet-related factors, chemokines, signaling pathways, and even microparticles are less explored in pancreatic cancer compared with other neoplasms (Supplementary Tables 1, 2).

Pancreatic cancer can manifest as exocrine or endocrine tumors, depending on the cell of origin. PDAC represents $90 \%$ of pancreatic malignancies. Patients are often diagnosed in the advanced staged, leading to an overall 5-year survival rate below $10 \%$. To find a suitable model is necessary for pancreatic cancer fundamental research and clinical application. There are different in vitro and in vivo models to study the process of pancreatic cancer (Supplementary Table 3). Compared with the advantages and disadvantages of these models, three-dimensional organoid culture will be an optimal choice to study pancreatic cancer progression. Organoids can maintain cell polarity, closely resemble molecular features, and interact with an extracellular matrix (Boj et al., 2015). Platelets as biomarkers are to be a platform for detecting pancreatic cancer (Sabrkhany et al., 2021). Cancer-associated platelets represent a liquid biopsy for diagnosis. In addition, platelets play an important role in thrombocytosis, cancer dissemination, immune surveillance, angiogenesis, recruitment of neutrophils/monocytes, and tumor cell extravasation. Establishing a co-culture model of platelets and pancreatic cancer is inevitable. Some research exists that develops co-culture pancreatic cancer organoids with immune cells, cancer-associated fibroblasts (CAF) (Tsai et al., 2018; Holokai et al., 2020), however, the 3D culture environment for platelets is still in a very early development stage. Rothan et al. (2014) found a 3D culture environment increases the efficacy of platelet-rich plasma release in prompting skin fibroblast differentiation and extracellular matrix formation.

\section{REFERENCES}

Abdol Razak, N., Elaskalani, O., and Metharom, P. (2017). Pancreatic Cancer-Induced neutrophil extracellular traps: a potential contributor to cancer-associated thrombosis. Int. J. Mol. Sci. 18:487. doi: 10.3390/ijms180 30487
Because platelets were defined as one part of blood cells, a perspective on applications of human blood cell culture and organoids is born (Seghatchian and Amiral, 2020). In fact, xenograft modes involving the transplantation of pancreatic tumor organoids have been shown to generate the full spectrum of tumor progression (Miyabayashi et al., 2020). Nevertheless, the development of co-culture pancreatic cancer organoids with platelets can imitate crosstalk between pancreatic cancer, extracellular matrix and platelets in tumor microenvironment. Accordingly, the underlying mechanism of interplay between pancreatic cancer and platelets will be uncovered. Furthermore, clinical and preclinical use of antiplatelet therapies in cancer will be improved, for example, aspirin, dipyridamole, RA-23 (cAMPPDE inhibitor), clopidogrel (Tzanakakis et al., 1993; Mezouar et al., 2015). Using platelets as a drug delivery system (DDS) was demonstrated by Lyde et al. (2015). Synthetic nanoparticles through coating with platelet membranes or platelet mimicry approach could be a smart DDS against cancer in the future (Burnouf et al., 2018). However, the double-sided effect of tumor microenvironment on platelets targeting nanoparticles is reported that the homing nanoparticles could realize the targeting ability, photo-thermal effect, and tumor immunotherapeutic ability in the accessible tumor but not the hypovascular tumor such as pancreatic cancer (Chen et al., 2018).

In summary, pancreatic cancer has effects on phenotype, aggregation, factors release, RNA profile of platelets, conversely, platelets influence pancreatic cancer progression. To fully reveal the crosstalk between platelets and pancreatic cancer is a prospective direction for clinical diagnosis and treatment.

\section{AUTHOR CONTRIBUTIONS}

Both authors listed have made a substantial, direct and intellectual contribution to the work, and approved it for publication.

\section{ACKNOWLEDGMENTS}

This work was financed by the European Union's Horizon 2020 Research and Innovation Program under the Marie SkłodowskaCurie grant agreement No. 86119 and grant St-54 from Medical Univeristy of Gdansk.

\section{SUPPLEMENTARY MATERIAL}

The Supplementary Material for this article can be found online at: https://www.frontiersin.org/articles/10.3389/fcell.2021. 749689/full\#supplementary-material

Andreasen, P. A., Egelund, R., and Petersen, H. H. (2000). The plasminogen activation system in tumor growth, invasion, and metastasis. Cell Mol. Life. Sci. 57, 25-40. doi: 10.1007/s000180050497

Angelou, A., Antoniou, E., Garmpis, N., Damaskos, C., Theocharis, S., and Margonis, G. A. (2018). The role of soluble CD40L ligand in human carcinogenesis. Anticancer. Res. 38, 3199-3201. doi: 10.21873/anticanres.12585 
Assoian, R. K., Komoriya, A., Meyers, C. A., Miller, D. M., and Sporn, M. B. (1983). Transforming growth factor-beta in human platelets. Identification of a major storage site, purification, and characterization. J. Biol. Chem. 258, 7155-7160.

Azab, A. K., Quang, P., Azab, F., Pitsillides, C., Thompson, B., Chonghaile, T., et al. (2012). P-selectin glycoprotein ligand regulates the interaction of multiple myeloma cells with the bone marrow microenvironment. Blood 119, 1468-1478. doi: 10.1182/blood-2011-07-368050

Bakewell, S. J., Nestor, P., Prasad, S., Tomasson, M. H., Dowland, N., Mehrotra, M., et al. (2003). Platelet and osteoclast beta 3 integrins are critical for bone metastasis. Proc. Natl. Acad. Sci. U S A. 100, 14205-14210. doi: 10.1073/pnas. 2234372100

Becker, K. A., Beckmann, N., Adams, C., Hessler, G., Kramer, M., Gulbins, E., et al. (2017). Melanoma cell metastasis via P-selectin-mediated activation of acid sphingomyelinase in platelets. Clin. Exp. Metastasis 34, 25-35. doi: 10.1007/ s10585-016-9826-9826

Behrens, D., Walther, W., and Fichtner, I. (2017). Pancreatic cancer models for translational research. Pharmacol. Ther. 173, 146-158. doi: 10.1016/j. pharmthera.2017.02.013

Bernat-Peguera, A., Simón-Extremera, P., da Silva-Diz, V., López, de Munain, M., Díaz-Gil, L., et al. (2019). PDGFR-induced autocrine SDF-1 signaling in cancer cells promotes metastasis in advanced skin carcinoma. Oncogene 38, 5021-5037. doi: 10.1038/s41388-019-0773-y

Best, M. G., Sol, N., Kooi, I., Tannous, J., Westerman, B. A., Rustenburg, F., et al. (2015). RNA-Seq of tumor-educated platelets enables blood-based pan-cancer, multiclass, and molecular pathway cancer diagnostics. Cancer Cell 28, 666-676. doi: $10.1016 /$ j.ccell.2015.09.018

Biau, J., Chautard, E., Court, F., Pereira, B., Verrelle, P., Devun, F., et al. (2016). Global conservation of protein status between cell lines and xenografts. Transl. Oncol. 9, 313-321. doi: 10.1016/j.tranon.2016.05.005

Boj, S. F., Hwang, C. I., Baker, L. A., Chio, I. I., Engle, D. D., Corbo, V., et al. (2015). Organoid models of human and mouse ductal pancreatic cancer. Cell 160, 324-338. doi: 10.1016/j.cell.2014.12.021

Boucharaba, A., Serre, C. M., Grès, S., Saulnier-Blache, J. S., Bordet, J. C., Guglielmi, J., et al. (2004). Platelet-derived lysophosphatidic acid supports the progression of osteolytic bone metastases in breast cancer. J. Clin. Invest. 114, 1714-1725. doi: $10.1172 /$ jci22123

Broadley, S. P., Plaumann, A., Coletti, R., Lehmann, C., Wanisch, A., Seidlmeier, A., et al. (2016). Dual-Track clearance of circulating bacteria balances rapid restoration of blood sterility with induction of adaptive immunity. Cell Host Microbe 20, 36-48. doi: 10.1016/j.chom.2016.05.023

Bruns, C. J., Solorzano, C. C., Harbison, M. T., Ozawa, S., Tsan, R., Fan, D., et al. (2000). Blockade of the epidermal growth factor receptor signaling by a novel tyrosine kinase inhibitor leads to apoptosis of endothelial cells and therapy of human pancreatic carcinoma. Cancer Res. 60, 2926-2935.

Burnouf, T., Burnouf, P. A., Wu, Y. W., Chuang, E. Y., Lu, L. S., and Goubran, H. (2018). Circulatory-cell-mediated nanotherapeutic approaches in disease targeting. Drug Discov. Today 23, 934-943. doi: 10.1016/j.drudis.2017. 08.012

Caine, G. J., Lip, G. Y., and Blann, A. D. (2004). Platelet-derived VEGF, Flt-1, angiopoietin-1 and P-selectin in breast and prostate cancer: further evidence for a role of platelets in tumour angiogenesis. Ann. Med. 36, 273-277. doi: 10.1080/07853890410026098

Caine, G. J., Ryan, P., Lip, G. Y., and Blann, A. D. (2007). Significant decrease in angiopoietin-1 and angiopoietin-2 after radical prostatectomy in prostate cancer patients. Cancer Lett. 251, 296-301. doi: 10.1016/j.canlet.2006.11.026

Camerer, E., Qazi, A. A., Duong, D. N., Cornelissen, I., Advincula, R., and Coughlin, S. R. (2004). Platelets, protease-activated receptors, and fibrinogen in hematogenous metastasis. Blood 104, 397-401. doi: 10.1182/blood-2004-020434

Carmi, Y., Dotan, S., Rider, P., Kaplanov, I., White, M. R., Baron, R., et al. (2013). The role of IL-1 $\beta$ in the early tumor cell-induced angiogenic response. J. Immunol. 190, 3500-3509. doi: 10.4049/jimmunol.1202769

Cervi, D., Yip, T. T., Bhattacharya, N., Podust, V. N., Peterson, J., Abou-Slaybi, A., et al. (2008). Platelet-associated PF-4 as a biomarker of early tumor growth. Blood 111, 1201-1207. doi: 10.1182/blood-2007-04-084798

Chen, H., Lan, X., Liu, M., Zhou, B., Wang, B., and Chen, P. (2013). Direct TGF- $\beta 1$ signaling between activated platelets and pancreatic cancer cells primes cisplatin insensitivity. Cell Biol. Int. 37, 478-484. doi: 10.1002/cbin.10067
Chen, X., Wang, Q., Liu, L., Sun, T., Zhou, W., Chen, Q., et al. (2018). Doublesided effect of tumor microenvironment on platelets targeting nanoparticles. Biomaterials 183, 258-267. doi: 10.1016/j.biomaterials.2018.07.005

Chen, Y., Wang, Y. R., Deng, G. C., and Dai, G. H. (2019). CA19-9 decrease and survival according to platelet level in patients with advanced pancreatic cancer. BMC Cancer 19:860. doi: 10.1186/s12885-019-6078-6072

Chiodoni, C., Iezzi, M., Guiducci, C., Sangaletti, S., Alessandrini, I., Ratti, C., et al. (2006). Triggering CD40 on endothelial cells contributes to tumor growth. J. Exp. Med. 203, 2441-2450. doi: 10.1084/jem.20060844

Cho, M. S., Li, J., Gonzalez-Delgado, R., Lee, H., Vasquez, M., He, T., et al. (2021). The effect of platelet $\mathrm{G}$ proteins on platelet extravasation and tumor growth in the murine model of ovarian cancer. Blood Adv. 5, 1947-1951. doi: 10.1182/ bloodadvances. 2020003410

Cho, M. S., Noh, K., Haemmerle, M., Li, D., Park, H., Hu, Q., et al. (2017). Role of ADP receptors on platelets in the growth of ovarian cancer. Blood 130, 1235-1242. doi: 10.1182/blood-2017-02-769893

Cognasse, F., Nguyen, K. A., Damien, P., McNicol, A., Pozzetto, B., HamzehCognasse, H., et al. (2015). The inflammatory role of platelets via their TLRs and siglec receptors. Front. Immunol. 6:83. doi: 10.3389/fimmu.2015.00083

Compagni, A., Wilgenbus, P., Impagnatiello, M. A., Cotten, M., and Christofori, G. (2000). Fibroblast growth factors are required for efficient tumor angiogenesis. Cancer Res. 60, 7163-7169.

Costanza, B., Rademaker, G., Tiamiou, A., De Tullio, P., Leenders, J., Blomme, A., et al. (2019). Transforming growth factor beta-induced, an extracellular matrix interacting protein, enhances glycolysis and promotes pancreatic cancer cell migration. Int. J. Cancer 145, 1570-1584. doi: 10.1002/ijc.32247

Coupland, L. A., and Parish, C. R. (2014). Platelets, selectins, and the control of tumor metastasis. Semin. Oncol. 41, 422-434. doi: 10.1053/j.seminoncol.2014. 04.003

D’Alessandro, R., Refolo, M. G., Lippolis, C., Giannuzzi, G., Carella, N., Messa, C., et al. (2014). Antagonism of sorafenib and regorafenib actions by platelet factors in hepatocellular carcinoma cell lines. BMC Cancer 14:351. doi: 10.1186/14712407-14-351

Date, K., Matsumoto, K., Kuba, K., Shimura, H., Tanaka, M., and Nakamura, T. (1998). Inhibition of tumor growth and invasion by a four-kringle antagonist (HGF/NK4) for hepatocyte growth factor. Oncogene 17, 3045-3054. doi: 10. 1038/sj.onc. 1202231

Davis, P. J., Mousa, S. A., Schechter, G. P., and Lin, H. Y. (2020). Platelet ATP, thyroid hormone receptor on integrin $\alpha \mathrm{v} \beta 3$ and Cancer metastasis. Horm. Cancer 11, 13-16. doi: 10.1007/s12672-019-00371-374

Di Vito, C., Navone, S. E., Marfia, G., Abdel Hadi, L., Mancuso, M. E., Pecci, A., et al. (2017). Platelets from glioblastoma patients promote angiogenesis of tumor endothelial cells and exhibit increased VEGF content and release. Platelets 28 , 585-594. doi: 10.1080/09537104.2016.1247208

Diaz, L. A., Marabelle, A., Delord, J.-P., Shapira-Frommer, R., Geva, R., Peled, N., et al. (2017). Pembrolizumab therapy for microsatellite instability high (MSI-H) colorectal cancer (CRC) and non-CRC. J. Clin. Oncol. 35, 3071-3071. doi: 10.1200/JCO.2017.35.15

Ding, X. Z., Hennig, R., and Adrian, T. E. (2003). Lipoxygenase and cyclooxygenase metabolism: new insights in treatment and chemoprevention of pancreatic cancer. Mol. Cancer 2:10. doi: 10.1186/1476-4598-2-10

Dovizio, M., Maier, T. J., Alberti, S., Di Francesco, L., Marcantoni, E., Münch, G., et al. (2013). Pharmacological inhibition of platelet-tumor cell cross-talk prevents platelet-induced overexpression of cyclooxygenase-2 in HT29 human colon carcinoma cells. Mol. Pharmacol. 84, 25-40. doi: 10.1124/mol.113.084988

Duan, B., Hu, J., Liu, H., Wang, Y., Li, H., Liu, S., et al. (2018). Genetic variants in the platelet-derived growth factor subunit B gene associated with pancreatic cancer risk. Int. J. Cancer 142, 1322-1331. doi: 10.1002/ijc.31171

Ducreux, M., Cuhna, A. S., Caramella, C., Hollebecque, A., Burtin, P., Goéré, D., et al. (2015). Cancer of the pancreas: ESMO clinical practice guidelines for diagnosis, treatment and follow-up. Ann. Oncol. 26(Suppl. 5), v56-v68. doi: 10.1093/annonc/mdv295

Egan, K., Cooke, N., and Kenny, D. (2014). Living in shear: platelets protect cancer cells from shear induced damage. Clin. Exp. Metastasis 31, 697-704. doi: 10.1007/s10585-014-9660-9667

El-Hariry, I., Pignatelli, M., and Lemoine, N. R. (2001). FGF-1 and FGF-2 modulate the E-cadherin/catenin system in pancreatic adenocarcinoma cell lines. $\mathrm{Br} . \mathrm{J}$. Cancer 84, 1656-1663. doi: 10.1054/bjoc.2001.1813 
Elaskalani, O., Domenichini, A., Abdol Razak, N. B., Dye, D. E., Falasca, M., and Metharom, P. (2020). Antiplatelet drug ticagrelor enhances chemotherapeutic efficacy by targeting the novel P2Y12-AKT pathway in pancreatic cancer cells. Cancers (Basel) 12:250. doi: 10.3390/cancers 12010250

Elaskalani, O., Falasca, M., Moran, N., Berndt, M. C., and Metharom, P. (2017). The role of platelet-derived ADP and ATP in promoting pancreatic cancer cell survival and gemcitabine resistance. Cancers (Basel) 9:142. doi: 10.3390/ cancers 9100142

Elwood, P. C., Morgan, G., Pickering, J. E., Galante, J., Weightman, A. L., Morris, D., et al. (2016). Aspirin in the treatment of cancer: reductions in metastatic spread and in mortality: a systematic review and meta-analyses of published studies. PLoS One 11:e0152402. doi: 10.1371/journal.pone.0152402

Felding-Habermann, B., O’Toole, T. E., Smith, J. W., Fransvea, E., Ruggeri, Z. M., Ginsberg, M. H., et al. (2001). Integrin activation controls metastasis in human breast cancer. Proc. Natl. Acad. Sci. U S A. 98, 1853-1858. doi: 10.1073/pnas.98. 4.1853

Ferreira, P. M., Bozbas, E., Tannetta, S. D., Alroqaiba, N., Zhou, R., Crawley, J. T. B., et al. (2020). Mode of induction of platelet-derived extracellular vesicles is a critical determinant of their phenotype and function. Sci. Rep. 10:18061. doi: 10.1038/s41598-020-73005-73003

Filippi, R., Depetris, I., and Satolli, M. A. (2021). Evaluating larotrectinib for the treatment of advanced solid tumors harboring an NTRK gene fusion. Expert Opin. Pharmacother. 22, 677-684. doi: 10.1080/14656566.2021.1876664

Fjällskog, M. L., Hessman, O., Eriksson, B., and Janson, E. T. (2007). Upregulated expression of PDGF receptor beta in endocrine pancreatic tumors and metastases compared to normal endocrine pancreas. Acta Oncol. 46, 741-746. doi: 10.1080/02841860601048388

Fujii, H., Egami, H., Chaney, W., Pour, P., and Pelling, J. (1990). Pancreatic ductal adenocarcinomas induced in Syrian hamsters by $\mathrm{N}$-nitrosobis(2oxopropyl)amine contain a c-Ki-ras oncogene with a point-mutated codon 12 . Mol. Carcinog. 3, 296-301. doi: 10.1002/mc.2940030510

Fujimoto, K., Hosotani, R., Wada, M., Lee, J. U., Koshiba, T., Miyamoto, Y., et al. (1998). Expression of two angiogenic factors, vascular endothelial growth factor and platelet-derived endothelial cell growth factor in human pancreatic cancer, and its relationship to angiogenesis. Eur. J. Cancer 34, 1439-1447. doi: 10.1016/s0959-8049(98)00069-60

Furukawa, T., Tabata, S., Yamamoto, M., Kawahara, K., Shinsato, Y., Minami, K., et al. (2018). Thymidine phosphorylase in cancer aggressiveness and chemoresistance. Pharmacol. Res. 132, 15-20. doi: 10.1016/j.phrs.2018.03.019

Gasperi, V., Vangapandu, C., Savini, I., Ventimiglia, G., Adorno, G., and Catani, M. V. (2019). Polyunsaturated fatty acids modulate the delivery of platelet microvesicle-derived microRNAs into human breast cancer cell lines. J. Nutr. Biochem. 74:108242. doi: 10.1016/j.jnutbio.2019.108242

Gong, J., Xie, J., Bedolla, R., Rivas, P., Chakravarthy, D., Freeman, J. W., et al. (2014). Combined targeting of STAT3/NF-кB/COX-2/EP4 for effective management of pancreatic cancer. Clin. Cancer Res. 20, 1259-1273. doi: 10. 1158/1078-0432.Ccr-13-1664

Goubran, H., Sabry, W., Kotb, R., Seghatchian, J., and Burnouf, T. (2015). Platelet microparticles and cancer: an intimate cross-talk. Transfus Apher. Sci. 53, 168-172. doi: 10.1016/j.transci.2015.10.014

Goubran, H. A., Kotb, R. R., Stakiw, J., Emara, M. E., and Burnouf, T. (2014). Regulation of tumor growth and metastasis: the role of tumor microenvironment. Cancer Growth Metastasis 7, 9-18. doi: 10.4137/cgm. S11285

Grande, R., Dovizio, M., Marcone, S., Szklanna, P. B., Bruno, A., Ebhardt, H. A., et al. (2019). Platelet-Derived microparticles from obese individuals: characterization of number, size, proteomics, and crosstalk with Cancer and endothelial cells. Front. Pharmacol. 10:7. doi: 10.3389/fphar.2019.00007

Gresele, P., Falcinelli, E., Sebastiano, M., and Momi, S. (2017). Matrix Metalloproteinases and Platelet Function. Prog. Mol. Biol. Transl. Sci. 147, 133-165. doi: 10.1016/bs.pmbts.2017.01.002

Guo, Y., Cui, W., Pei, Y., and Xu, D. (2019). Platelets promote invasion and induce epithelial to mesenchymal transition in ovarian cancer cells by TGF$\beta$ signaling pathway. Gynecol. Oncol. 153, 639-650. doi: 10.1016/j.ygyno.2019. 02.026

Haemmerle, M., Stone, R. L., Menter, D. G., Afshar-Kharghan, V., and Sood, A. K. (2018). The platelet lifeline to Cancer: challenges and opportunities. Cancer Cell 33, 965-983. doi: 10.1016/j.ccell.2018.03.002
Haqq, J., Howells, L. M., Garcea, G., and Dennison, A. R. (2016). Targeting pancreatic cancer using a combination of gemcitabine with the omega-3 polyunsaturated fatty acid emulsion, Lipidem ${ }^{\text {TM }}$. Mol. Nutr. Food Res. 60, 1437-1447. doi: 10.1002/mnfr.201500755

Haschemi, R., Gockel, L. M., Bendas, G., and Schlesinger, M. (2021). A combined activity of thrombin and p-selectin is essential for platelet activation by pancreatic Cancer cells. Int. J. Mol. Sci. 22:3323. doi: 10.3390/ijms22073323

Hayashi, Y., and Hasegawa, T. (1971). Experimental pancreatic tumor in rats after intravenous injection of 4-hydroxyaminoquinoline 1-oxide. Gan 62, 329-330.

Heinmöller, E., Schropp, T., Kisker, O., Simon, B., Seitz, R., and Weinel, R. J. (1995). Tumor cell-induced platelet aggregation in vitro by human pancreatic cancer cell lines. Scand. J. Gastroenterol. 30, 1008-1016. doi: 10.3109/ 00365529509096346

Heller, A., Angelova, A. L., Bauer, S., Grekova, S. P., Aprahamian, M., Rommelaere, J., et al. (2016). Establishment and characterization of a novel cell line, ASAN$\mathrm{PaCa}$, derived from human adenocarcinoma arising in intraductal papillary mucinous neoplasm of the pancreas. Pancreas 45, 1452-1460. doi: 10.1097/mpa. 0000000000000673

Helley, D., Banu, E., Bouziane, A., Banu, A., Scotte, F., Fischer, A. M., et al. (2009). Platelet microparticles: a potential predictive factor of survival in hormonerefractory prostate cancer patients treated with docetaxel-based chemotherapy. Eur. Urol. 56, 479-484. doi: 10.1016/j.eururo.2008.06.038

Hellum, M., Franco-Lie, I., Øvstebø, R., Hauge, T., and Henriksson, C. E. (2017). The effect of corn trypsin inhibitor, anti-tissue factor pathway inhibitor antibodies and phospholipids on microvesicle-associated thrombin generation in patients with pancreatic cancer and healthy controls. PLoS One 12:e0184579. doi: 10.1371/journal.pone.0184579

Hezel, A. F., Kimmelman, A. C., Stanger, B. Z., Bardeesy, N., and Depinho, R. A. (2006). Genetics and biology of pancreatic ductal adenocarcinoma. Genes Dev. 20, 1218-1249. doi: 10.1101/gad.1415606

Hinz, S., Pagerols-Raluy, L., Oberg, H. H., Ammerpohl, O., Grüssel, S., Sipos, B., et al. (2007). Foxp3 expression in pancreatic carcinoma cells as a novel mechanism of immune evasion in cancer. Cancer Res. 67, 8344-8350. doi: 10.1158/0008-5472.Can-06-3304

Hisada, Y., Ay, C., Auriemma, A. C., Cooley, B. C., and Mackman, N. (2017). Human pancreatic tumors grown in mice release tissue factor-positive microvesicles that increase venous clot size. J. Thromb. Haemost. 15, 2208-2217. doi: 10.1111/jth.13809

Ho, M. Y., Tang, S. J., Ng, W. V., Yang, W., Leu, S. J., Lin, Y. C., et al. (2010). Nucleotide-binding domain of phosphoglycerate kinase 1 reduces tumor growth by suppressing COX-2 expression. Cancer Sci. 101, 2411-2416. doi: 10.1111/j.1349-7006.2010.01691.x

Hoffmann, A. C., Mori, R., Vallbohmer, D., Brabender, J., Drebber, U., Baldus, S. E., et al. (2008). High expression of heparanase is significantly associated with dedifferentiation and lymph node metastasis in patients with pancreatic ductal adenocarcinomas and correlated to PDGFA and via HIF1a to HB-EGF and bFGF. J. Gastrointest. Surg. 12, 1674-1681. doi: 10.1007/s11605-008-0628-622

Holokai, L., Chakrabarti, J., Lundy, J., Croagh, D., Adhikary, P., Richards, S. S., et al. (2020). Murine- and human-derived autologous organoid/immune cell Cocultures as pre-clinical models of pancreatic ductal adenocarcinoma. Cancers (Basel) 12:3816. doi: 10.3390/cancers12123816

Hruban, R. H., Maitra, A., Kern, S. E., and Goggins, M. (2007). Precursors to pancreatic cancer. Gastroenterol. Clin. North Am. 36, 831iv-849iv. doi: 10.1016/ j.gtc.2007.08.012

Inoue, K., Ohtsuka, H., Tachikawa, M., Motoi, F., Shijo, M., Douchi, D., et al. (2017). MK2461, a multitargeted kinase inhibitor, suppresses the progression of pancreatic Cancer by disrupting the interaction between pancreatic Cancer cells and stellate cells. Pancreas 46, 557-566. doi: 10.1097/mpa.0000000000000778

Jain, S., Russell, S., and Ware, J. (2009). Platelet glycoprotein VI facilitates experimental lung metastasis in syngenic mouse models. J. Thromb. Haemost. 7, 1713-1717. doi: 10.1111/j.1538-7836.2009.03559.x

Jain, S., Zuka, M., Liu, J., Russell, S., Dent, J., Guerrero, J. A., et al. (2007). Platelet glycoprotein Ib alpha supports experimental lung metastasis. Proc. Natl. Acad. Sci. U S A. 104, 9024-9028. doi: 10.1073/pnas.0700625104

Jia, Y., Zhang, S., Miao, L., Wang, J., Jin, Z., Gu, B., et al. (2015). Activation of platelet protease-activated receptor-1 induces epithelial-mesenchymal transition and chemotaxis of colon cancer cell line SW620. Oncol. Rep. 33, 2681-2688. doi: 10.3892/or.2015.3897 
Jiang, L., Luan, Y., Miao, X., Sun, C., Li, K., Huang, Z., et al. (2017). Platelet releasate promotes breast cancer growth and angiogenesis via VEGFintegrin cooperative signalling. Br. J. Cancer 117, 695-703. doi: 10.1038/bjc.20 17.214

Jiang, Y., He, R., Jiang, Y., Liu, D., Tao, L., Yang, M., et al. (2019). Transcription factor NFAT5 contributes to the glycolytic phenotype rewiring and pancreatic cancer progression via transcription of PGK1. Cell Death Dis. 10:948. doi: 10.1038/s41419-019-2072-2075

Jimenez, R. E., Hartwig, W., Antoniu, B. A., Compton, C. C., Warshaw, A. L., and Fernández-Del Castillo, C. (2000). Effect of matrix metalloproteinase inhibition on pancreatic cancer invasion and metastasis: an additive strategy for cancer control. Ann. Surg. 231, 644-654. doi: 10.1097/00000658-200005000200005004

Jun, E., Jung, J., Jeong, S. Y., Choi, E. K., Kim, M. B., Lee, J. S., et al. (2016). Surgical and oncological factors affecting the successful engraftment of patient-derived xenografts in pancreatic ductal adenocarcinoma. Anticancer. Res. 36, 517-521.

Kahlert, C., Fiala, M., Musso, G., Halama, N., Keim, S., Mazzone, M., et al. (2014). Prognostic impact of a compartment-specific angiogenic marker profile in patients with pancreatic cancer. Oncotarget 5, 12978-12989. doi: 10.18632/ oncotarget.2651

Kanazawa, S., Nomura, S., Kuwana, M., Muramatsu, M., Yamaguchi, K., and Fukuhara, S. (2003). Monocyte-derived microparticles may be a sign of vascular complication in patients with lung cancer. Lung Cancer 39, 145-149. doi: 10. 1016/s0169-5002(02)00441-445

Kang, X., Lin, Z., Xu, M., Pan, J., and Wang, Z. W. (2019). Deciphering role of FGFR signalling pathway in pancreatic cancer. Cell Prolif. 52:e12605. doi: $10.1111 /$ cpr.12605

Kano, M. R., Bae, Y., Iwata, C., Morishita, Y., Yashiro, M., Oka, M., et al. (2007). Improvement of cancer-targeting therapy, using nanocarriers for intractable solid tumors by inhibition of TGF-beta signaling. Proc. Natl. Acad. Sci. U S A. 104, 3460-3465. doi: 10.1073/pnas.0611660104

Karayiannakis, A. J., Bolanaki, H., Syrigos, K. N., Asimakopoulos, B., Polychronidis, A., Anagnostoulis, S., et al. (2003). Serum vascular endothelial growth factor levels in pancreatic cancer patients correlate with advanced and metastatic disease and poor prognosis. Cancer Lett. 194, 119-124. doi: 10.1016/s0304-3835(03)00047-48

Kasper, H. U., Ebert, M., Malfertheiner, P., Roessner, A., Kirkpatrick, C. J., and Wolf, H. K. (2001). Expression of thrombospondin-1 in pancreatic carcinoma: correlation with microvessel density. Virchows Arch. 438, 116-120. doi: 10.1007/ s004280000302

Kerr, B. A., Harris, K. S., Shi, L., Willey, J. S., Soto-Pantoja, D. R., and Byzova, T. V. (2021). Platelet TSP-1 controls prostate cancer-induced osteoclast differentiation and bone marrow-derived cell mobilization through TGF $\beta-1$. Am J. Clin. Exp. Urol. 9, 18-31.

Khalaf, N., Yuan, C., Hamada, T., Cao, Y., Babic, A., Morales-Oyarvide, V., et al. (2018). Regular use of aspirin or non-aspirin nonsteroidal anti-inflammatory drugs is not associated with risk of incident pancreatic cancer in two large cohort studies. Gastroenterology 154, 1380-1390.e5. doi: 10.1053/j.gastro.2017. 12.001

Khorana, A. A., Francis, C. W., Menzies, K. E., Wang, J. G., Hyrien, O., Hathcock, J., et al. (2008). Plasma tissue factor may be predictive of venous thromboembolism in pancreatic cancer. J. Thromb. Haemost. 6, 1983-1985. doi: 10.1111/j.1538-7836.2008.03156.x

Khorana, A. A., Hu, Y. C., Ryan, C. K., Komorowski, R. A., Hostetter, G., and Ahrendt, S. A. (2005). Vascular endothelial growth factor and DPC4 predict adjuvant therapy outcomes in resected pancreatic cancer. J. Gastrointest. Surg. 9, 903-911. doi: 10.1016/j.gassur.2005.06.021

Kitajima, Y., Ide, T., Ohtsuka, T., and Miyazaki, K. (2008). Induction of hepatocyte growth factor activator gene expression under hypoxia activates the hepatocyte growth factor/c-Met system via hypoxia inducible factor-1 in pancreatic cancer. Cancer Sci. 99, 1341-1347. doi: 10.1111/j.1349-7006.2008.00828.x

Komatsu, S., Ichikawa, D., Miyamae, M., Kawaguchi, T., Morimura, R., Hirajima, S., et al. (2015). Malignant potential in pancreatic neoplasm; new insights provided by circulating miR-223 in plasma. Expert Opin. Biol. Ther. 15, 773785. doi: $10.1517 / 14712598.2015 .1029914$

Kong, K., Guo, M., Liu, Y., and Zheng, J. (2020). Progress in animal models of pancreatic ductal adenocarcinoma. J. Cancer 11, 1555-1567. doi: 10.7150/jca. 37529
Kubala, M. H., and DeClerck, Y. A. (2019). The plasminogen activator inhibitor1 paradox in cancer: a mechanistic understanding. Cancer Metastasis Rev. 38, 483-492. doi: 10.1007/s10555-019-09806-9804

Kuznetsov, H. S., Marsh, T., Markens, B. A., Castaño, Z., Greene-Colozzi, A., Hay, S. A., et al. (2012). Identification of luminal breast cancers that establish a tumor-supportive macroenvironment defined by proangiogenic platelets and bone marrow-derived cells. Cancer Discov. 2, 1150-1165. doi: 10.1158/21598290.Cd-12-0216

Labelle, M., Begum, S., and Hynes, R. O. (2014). Platelets guide the formation of early metastatic niches. Proc. Natl. Acad. Sci. U S A. 111, E3053-E3061. doi: 10.1073/pnas.1411082111

Le, X., Shi, Q., Wang, B., Xiong, Q., Qian, C., Peng, Z., et al. (2000). Molecular regulation of constitutive expression of interleukin-8 in human pancreatic adenocarcinoma. J. Interferon Cytokine Res. 20, 935-946. doi: 10.1089/ 10799900050198372

Lee, J., Lee, J., Yun, J. H., Choi, C., Cho, S., Kim, S. J., et al. (2017). Autocrine DUSP28 signaling mediates pancreatic cancer malignancy via regulation of PDGF-A. Sci. Rep. 7:12760. doi: 10.1038/s41598-017-13023-w

Lembeck, A. L., Posch, F., Klocker, E. V., Szkandera, J., Schlick, K., Stojakovic, T., et al. (2019). Large platelet size is associated with poor outcome in patients with metastatic pancreatic cancer. Clin. Chem. Lab. Med. 57, 740-744. doi: 10.1515/cclm-2018-2016

Li, S., Wei, X., He, J., Tian, X., Yuan, S., and Sun, L. (2018). Plasminogen activator inhibitor-1 in cancer research. Biomed. Pharmacother. 105, 83-94. doi: 10.1016/ j.biopha.2018.05.119

Li, T., Guo, T., Liu, H., Jiang, H., and Wang, Y. (2021). Platelet-derived growth factor-BB mediates pancreatic cancer malignancy via regulation of the Hippo/Yes-associated protein signaling pathway. Oncol. Rep. 45, 83-94. doi: 10.3892/or.2020.7859

Liao, Y., Mu, G., Zhang, L., Zhou, W., Zhang, J., and Yu, H. (2013). Lysophosphatidic acid stimulates activation of focal adhesion kinase and paxillin and promotes cell motility, via LPA1-3, in human pancreatic cancer. Dig. Dis. Sci. 58, 3524-3533. doi: 10.1007/s10620-013-2878-2874

Logsdon, C. D., Arumugam, T., and Ramachandran, V. (2015). Animal models of gastrointestinal and liver diseases. the difficulty of animal modeling of pancreatic cancer for preclinical evaluation of therapeutics. Am. J. Physiol. Gastrointest Liver Physiol. 309, G283-G291. doi: 10.1152/ajpgi.00169.2015

Losurdo, G., Principi, M., Girardi, B., Pricci, M., Barone, M., Ierardi, E., et al. (2018). Histamine and histaminergic receptors in colorectal Cancer: from basic science to evidence-based medicine. Anticancer Agents Med. Chem. 18, 15-20. doi: $10.2174 / 1871520616666160321115349$

Łukaszewicz-Zając, M., Gryko, M., Pączek, S., Szmitkowski, M., Kędra, B., and Mroczko, B. (2019). Matrix metalloproteinase 2 (MMP-2) and its tissue inhibitor 2 (TIMP-2) in pancreatic cancer (PC). Oncotarget 10, 395-403. doi: 10.18632/oncotarget.26571

Lyde, R., Sabatino, D., Sullivan, S. K., and Poncz, M. (2015). Platelet-delivered therapeutics. J. Thromb. Haemost. 13(Suppl. 1), S143-S150. doi: 10.1111/jth. 12938

Maione, T. E., Gray, G. S., Petro, J., Hunt, A. J., Donner, A. L., Bauer, S. I., et al. (1990). Inhibition of angiogenesis by recombinant human platelet factor- 4 and related peptides. Science 247, 77-79. doi: 10.1126/science.1688470

Malehmir, M., Pfister, D., Gallage, S., Szydlowska, M., Inverso, D., Kotsiliti, E., et al. (2019). Platelet GPIb $\alpha$ is a mediator and potential interventional target for NASH and subsequent liver cancer. Nat. Med. 25, 641-655. doi: 10.1038/ s41591-019-0379-375

Mammadova-Bach, E., Zigrino, P., Brucker, C., Bourdon, C., Freund, M., De Arcangelis, A., et al. (2016). Platelet integrin $\alpha 6 \beta 1$ controls lung metastasis through direct binding to cancer cell-derived ADAM9. JCI Insight 1:e88245. doi: $10.1172 /$ jci.insight. 88245

Marcolino, E., Siddiqui, Y. H., van den Bosch, M., Poole, A. W., Jayaraman, P. S., and Gaston, K. (2020). Blood platelets stimulate cancer extravasation through TGF $\beta$-mediated downregulation of PRH/HHEX. Oncogenesis 9:10. doi: 10.1038/s41389-020-0189-180

Massari, N. A., Nicoud, M. B., and Medina, V. A. (2020). Histamine receptors and cancer pharmacology: an update. Br. J. Pharmacol. 177, 516-538. doi: 10.1111/bph.14535

Matejcic, M., Lesueur, F., Biessy, C., Renault, A. L., Mebirouk, N., Yammine, S., et al. (2018). Circulating plasma phospholipid fatty acids and risk of pancreatic 
cancer in a large European cohort. Int. J. Cancer 143, 2437-2448. doi: 10.1002/ ijc. 31797

Mezouar, S., Darbousset, R., Dignat-George, F., Panicot-Dubois, L., and Dubois, C. (2015). Inhibition of platelet activation prevents the P-selectin and integrindependent accumulation of cancer cell microparticles and reduces tumor growth and metastasis in vivo. Int. J. Cancer 136, 462-475. doi: 10.1002/ijc. 28997

Michael, J. V., Wurtzel, J. G. T., Mao, G. F., Rao, A. K., Kolpakov, M. A., Sabri, A., et al. (2017). Platelet microparticles infiltrating solid tumors transfer miRNAs that suppress tumor growth. Blood 130, 567-580. doi: 10.1182/blood-2016-11751099

Mitrugno, A., Sylman, J. L., Ngo, A. T., Pang, J., Sears, R. C., Williams, C. D., et al. (2017). Aspirin therapy reduces the ability of platelets to promote colon and pancreatic cancer cell proliferation: implications for the oncoprotein c-MYC. Am. J. Physiol. Cell Physiol. 312, C176-C189. doi: 10.1152/ajpcell.00196.2016

Miyabayashi, K., Baker, L. A., Deschênes, A., Traub, B., Caligiuri, G., Plenker, D., et al. (2020). Intraductal transplantation models of human pancreatic ductal adenocarcinoma reveal progressive transition of molecular subtypes. Cancer Discov. 10, 1566-1589. doi: 10.1158/2159-8290.Cd-20-0133

Miyashita, T., Tajima, H., Makino, I., Nakagawara, H., Kitagawa, H., Fushida, S., et al. (2015). Metastasis-promoting role of extravasated platelet activation in tumor. J. Surg. Res. 193, 289-294. doi: 10.1016/j.jss.2014.07.037

Murphy, B., Yin, H., Maris, J. M., Kolb, E. A., Gorlick, R., Reynolds, C. P., et al. (2016). Evaluation of alternative in vivo drug screening methodology: a single mouse analysis. Cancer Res. 76, 5798-5809. doi: 10.1158/0008-5472.Can-160122

Nagahashi, M., Takabe, K., Terracina, K. P., Soma, D., Hirose, Y., Kobayashi, T., et al. (2014). Sphingosine-1-phosphate transporters as targets for cancer therapy. Biomed. Res. Int. 2014:651727. doi: 10.1155/2014/651727

Nakamura, T., Kuwai, T., Kim, J. S., Fan, D., Kim, S. J., and Fidler, I. J. (2007). Stromal metalloproteinase- 9 is essential to angiogenesis and progressive growth of orthotopic human pancreatic cancer in parabiont nude mice. Neoplasia 9, 979-986. doi: 10.1593/neo.07742

Neal, J. T., Li, X., Zhu, J., Giangarra, V., Grzeskowiak, C. L., Ju, J., et al. (2018). Organoid modeling of the tumor immune microenvironment. Cell 175, 19721988.e16. doi: 10.1016/j.cell.2018.11.021

Negoi, I., Beuran, M., Hostiuc, S., El-Hussuna, A., and de-Madaria, E. (2019). Platelet-to-lymphocyte ratio and CA19-9 are simple and informative prognostic factors in patients with resected pancreatic cancer. Hepatobiliary Pancreat. Dis. Int. 18, 203-205. doi: 10.1016/j.hbpd.2019.03.011

Nilsson, R. J., Balaj, L., Hulleman, E., van Rijn, S., Pegtel, D. M., Walraven, M., et al. (2011). Blood platelets contain tumor-derived RNA biomarkers. Blood 118, 3680-3683. doi: 10.1182/blood-2011-03-344408

Obermeier, H. L., Riedl, J., Ay, C., Koder, S., Quehenberger, P., Bartsch, R., et al. (2019). The role of ADAMTS-13 and von willebrand factor in cancer patients: results from the vienna cancer and thrombosis study. Res. Pract. Thromb Haemost 3, 503-514. doi: 10.1002/rth2.12197

Ohlund, D., Ardnor, B., Oman, M., Naredi, P., and Sund, M. (2008). Expression pattern and circulating levels of endostatin in patients with pancreas cancer. Int. J. Cancer 122, 2805-2810. doi: 10.1002/ijc.23468

Olsen, R. S., Dimberg, J., Geffers, R., and Wågsäter, D. (2019). Possible role and therapeutic target of PDGF-D signalling in colorectal Cancer. Cancer Invest 37, 99-112. doi: 10.1080/07357907.2019.1576191

Oria, V. O., Lopatta, P., Schmitz, T., Preca, B. T., Nyström, A., Conrad, C., et al. (2019). ADAM9 contributes to vascular invasion in pancreatic ductal adenocarcinoma. Mol. Oncol. 13, 456-479. doi: 10.1002/1878-0261.1 2426

Palumbo, J. S., Talmage, K. E., Massari, J. V., La Jeunesse, C. M., Flick, M. J., Kombrinck, K. W., et al. (2005). Platelets and fibrin(ogen) increase metastatic potential by impeding natural killer cell-mediated elimination of tumor cells. Blood 105, 178-185. doi: 10.1182/blood-2004-06-2272

Pang, B., Xu, X., Lu, Y., Jin, H., Yang, R., Jiang, C., et al. (2019). Prediction of new targets and mechanisms for quercetin in the treatment of pancreatic cancer, colon cancer, and rectal cancer. Food Funct. 10, 5339-5349. doi: 10.1039/ c9fo01168d

Parizadeh, S. M., Jafarzadeh-Esfehani, R., Fazilat-Panah, D., Hassanian, S. M., Shahidsales, S., Khazaei, M., et al. (2019). The potential therapeutic and prognostic impacts of the c-MET/HGF signaling pathway in colorectal cancer. IUBMB Life 71, 802-811. doi: 10.1002/iub.2063
Pasanisi, P., Venturelli, E., Morelli, D., Fontana, L., Secreto, G., and Berrino, F. (2008). Serum insulin-like growth factor-I and platelet-derived growth factor as biomarkers of breast cancer prognosis. Cancer Epidemiol. Biomarkers. Prev. 17, 1719-1722.

Pascual, G., Avgustinova, A., Mejetta, S., Martín, M., Castellanos, A., Attolini, C. S., et al. (2017). Targeting metastasis-initiating cells through the fatty acid receptor CD36. Nature 541, 41-45. doi: 10.1038/nature20791

Patmore, S., Dhami, S. P. S., and O'Sullivan, J. M. (2020). Von Willebrand factor and cancer; metastasis and coagulopathies. J. Thromb. Haemost. 18, 2444-2456. doi: $10.1111 /$ jth. 14976

Perollet, C., Han, Z. C., Savona, C., Caen, J. P., and Bikfalvi, A. (1998). Platelet factor 4 modulates fibroblast growth factor 2 (FGF-2) activity and inhibits FGF-2 dimerization. Blood 91, 3289-3299.

Peterson, J. E., Zurakowski, D., Italiano, J. E. Jr., Michel, L. V., Connors, S., et al. (2012). VEGF, PF4 and PDGF are elevated in platelets of colorectal cancer patients. Angiogenesis 15, 265-273. doi: 10.1007/s10456-012-9259-z

Pilatova, K., Greplova, K., Demlova, R., Bencsikova, B., Klement, G. L., and Zdrazilova-Dubska, L. (2013). Role of platelet chemokines, PF-4 and CTAP-III, in cancer biology. J. Hematol. Oncol. 6:42. doi: 10.1186/1756-8722-6-42

Pinedo, H. M., Verheul, H. M., D’Amato, R. J., and Folkman, J. (1998). Involvement of platelets in tumour angiogenesis? Lancet 352, 1775-1777. doi: 10.1016/ s0140-6736(98)05095-5098

Plantureux, L., Mège, D., Crescence, L., Carminita, E., Robert, S., Cointe, S., et al. (2020). The interaction of platelets with colorectal cancer cells inhibits tumor growth but promotes metastasis. Cancer Res. 80, 291-303. doi: 10.1158/00085472.Can-19-1181

Pothula, S. P., Xu, Z., Goldstein, D., Pirola, R. C., Wilson, J. S., and Apte, M. V. (2020). Targeting HGF/c-MET axis in pancreatic Cancer. Int. J. Mol. Sci. 21:9170. doi: 10.3390/ijms21239170

Prokopchuk, O., Grünwald, B., Nitsche, U., Jäger, C., Prokopchuk, O. L., Schubert, E. C., et al. (2018). Elevated systemic levels of the matrix metalloproteinase inhibitor TIMP-1 correlate with clinical markers of cachexia in patients with chronic pancreatitis and pancreatic cancer. BMC Cancer 18:128. doi: 10.1186/ s12885-018-4055-4059

Qi, C., Wei, B., Zhou, W., Yang, Y., Li, B., Guo, S., et al. (2015). P-selectinmediated platelet adhesion promotes tumor growth. Oncotarget 6, 6584-6596. doi: 10.18632/oncotarget.3164

Qin, S., Lu, Y., Chen, S., Hu, Z., Chen, H., Zhong, J., et al. (2019). The relationship of neutrophil-to-lymphocyte ratio or platelet-to-lymphocyte ratio and pancreatic Cancer in patients with Type 2 diabetes. Clin. Lab. 65. doi: 10.7754/Clin.Lab.2019.181226

Radziwon-Balicka, A., Medina, C., O’Driscoll, L., Treumann, A., Bazou, D., Inkielewicz-Stepniak, I., et al. (2012). Platelets increase survival of adenocarcinoma cells challenged with anticancer drugs: mechanisms and implications for chemoresistance. Br. J. Pharmacol. 167, 787-804. doi: 10.1111/ j.1476-5381.2012.01991.x

Rahbari, N. N., Schmidt, T., Falk, C. S., Hinz, U., Herber, M., Bork, U., et al. (2011). Expression and prognostic value of circulating angiogenic cytokines in pancreatic cancer. BMC Cancer 11:286. doi: 10.1186/1471-2407-11-286

Ren, J., He, J., Zhang, H., Xia, Y., Hu, Z., Loughran, P., et al. (2021). Platelet TLR4-ERK5 axis facilitates NET-Mediated capturing of circulating tumor cells and distant metastasis after surgical stress. Cancer Res. 81, 2373-2385. doi: 10.1158/0008-5472.Can-20-3222

Riedl, J., Preusser, M., Nazari, P. M., Posch, F., Panzer, S., Marosi, C., et al. (2017). Podoplanin expression in primary brain tumors induces platelet aggregation and increases risk of venous thromboembolism. Blood 129, 1831-1839. doi: 10.1182/blood-2016-06-720714

Rothan, H. A., Djordjevic, I., Bahrani, H., Paydar, M., Ibrahim, F., Abd Rahmanh, N., et al. (2014). Three-dimensional culture environment increases the efficacy of platelet rich plasma releasate in prompting skin fibroblast differentiation and extracellular matrix formation. Int. J. Med. Sci. 11, 1029-1038. doi: 10.7150/ ijms.8895

Rowland-Goldsmith, M. A., Maruyama, H., Matsuda, K., Idezawa, T., Ralli, M., Ralli, S., et al. (2002). Soluble type II transforming growth factor-beta receptor attenuates expression of metastasis-associated genes and suppresses pancreatic cancer cell metastasis. Mol. Cancer Ther. 1, 161-167.

Ruggeri, Z. M., and Jackson, S. P. (2013). "Chapter 20 - platelet thrombus formation in flowing blood," in Platelets, 3rd Edn, ed. A. D. Michelson (Cambridge, MA: Academic Press), 399-423. 
Sabrkhany, S., Kuijpers, M. J. E., Knol, J. C., Olde Damink, S. W. M., Dingemans, A. C., Verheul, H. M., et al. (2018). Exploration of the platelet proteome in patients with early-stage cancer. J. Proteomics 177, 65-74. doi: 10.1016/j.jprot. 2018.02.011

Sabrkhany, S., Kuijpers, M. J. E., Oude Egbrink, M. G. A., and Griffioen, A. W. (2021). Platelets as messengers of early-stage cancer. Cancer Metastasis Rev. 40, 563-573. doi: 10.1007/s10555-021-09956-9954

Sabrkhany, S., Kuijpers, M. J. E., van Kuijk, S. M. J., Sanders, L., Pineda, S., Olde Damink, S. W. M., et al. (2017). A combination of platelet features allows detection of early-stage cancer. Eur. J. Cancer 80, 5-13. doi: 10.1016/j.ejca.2017. 04.010

Sahraei, M., Roy, L. D., Curry, J. M., Teresa, T. L., Nath, S., Besmer, D., et al. (2012). MUC1 regulates PDGFA expression during pancreatic cancer progression. Oncogene 31, 4935-4945. doi: 10.1038/onc.2011.651

Saito, M., Ichikawa, J., Ando, T., Schoenecker, J. G., Ohba, T., Koyama, K., et al. (2018). Platelet-Derived TGF- $\beta$ induces tissue factor expression via the smad 3 pathway in osteosarcoma cells. J. Bone. Miner. Res. 33, 2048-2058. doi: 10.1002/ jbmr.3537

Salem, M. S. H., Abdel Aziz, Y. M., Elgawish, M. S., Said, M. M., and Abouzid, K. A. M. (2020). Design, synthesis, biological evaluation and molecular modeling study of new thieno[2,3-d]pyrimidines with anti-proliferative activity on pancreatic cancer cell lines. Bioorg. Chem. 94:103472. doi: 10.1016/j.bioorg. 2019.103472

Sangkuhl, K., Shuldiner, A. R., Klein, T. E., and Altman, R. B. (2011). Platelet aggregation pathway. Pharmacogenet Genomics 21, 516-521. doi: 10.1097/FPC. 0b013e3283406323

Sarrouilhe, D., and Mesnil, M. (2019). Serotonin and human cancer: a critical view. Biochimie 161, 46-50. doi: 10.1016/j.biochi.2018.06.016

Sarsour, E. H., Son, J. M., Kalen, A. L., Xiao, W., Du, J., Alexander, M. S., et al. (2020). Arachidonate 12-lipoxygenase and 12-hydroxyeicosatetraenoic acid contribute to stromal aging-induced progression of pancreatic cancer. J. Biol. Chem. 295, 6946-6957. doi: 10.1074/jbc.RA120.012798

Sawai, H., Takeyama, H., Yamamoto, M., Furuta, A., Funahashi, H., Okada, Y., et al. (2003). Enhancement of integrins by interleukin-1alpha, and their relationship with metastatic and invasive behavior of human pancreatic ductal adenocarcinoma cells. J. Surg. Oncol. 82, 51-56. doi: 10.1002/jso.10187

Seghatchian, J., and Amiral, J. (2020). Spotlight on the current perspectives on applications of human blood cell culture and organoids: introductory remarks. Transfus Apher Sci. 59:102861. doi: 10.1016/j.transci.2020.102861

Shirai, Y., Shiba, H., Haruki, K., Horiuchi, T., Saito, N., Fujiwara, Y., et al. (2017). Preoperative platelet-to-albumin ratio predicts prognosis of patients with pancreatic ductal adenocarcinoma after pancreatic resection. Anticancer. Res. 37, 787-793. doi: 10.21873/anticanres.11378

Sierko, E., and Wojtukiewicz, M. Z. (2004). Platelets and angiogenesis in malignancy. Semin. Thromb Hemost 30, 95-108. doi: 10.1055/s-2004-822974

Sleightholm, R. L., Neilsen, B. K., Li, J., Steele, M. M., Singh, R. K., Hollingsworth, M. A., et al. (2017). Emerging roles of the CXCL12/CXCR4 axis in pancreatic cancer progression and therapy. Pharmacol. Ther. 179, 158-170. doi: 10.1016/j. pharmthera.2017.05.012

Smith, B. A. H., and Bertozzi, C. R. (2021). The clinical impact of glycobiology: targeting selectins, siglecs and mammalian glycans. Nat. Rev. Drug Discov. 20, 217-243. doi: 10.1038/s41573-020-00093-91

Song, W., Tian, C., Wang, K., Zhang, R. J., and Zou, S. B. (2017). Preoperative platelet lymphocyte ratio as independent predictors of prognosis in pancreatic cancer: a systematic review and meta-analysis. PLoS One 12:e0178762. doi: 10.1371/journal.pone.0178762

Starlinger, P., Alidzanovic, L., Schauer, D., Brugger, P., Sommerfeldt, S., Kuehrer, I., et al. (2011). Platelet-stored angiogenesis factors: clinical monitoring is prone to artifacts. Dis. Markers 31, 55-65. doi: 10.3233/dma-2011-2798

Stec, M., Baj-Krzyworzeka, M., Baran, J., Węglarczyk, K., Zembala, M., Barbasz, J., et al. (2015). Isolation and characterization of circulating micro(nano)vesicles in the plasma of colorectal cancer patients and their interactions with tumor cells. Oncol. Rep. 34, 2768-2775. doi: 10.3892/or.2015.4228

Sun, J., Li, Y., Liu, L., Jiang, Z., and Liu, G. (2019). Aspirin use and pancreatic cancer risk: a systematic review of observational studies. Medicine (Baltimore) 98:e18033. doi: 10.1097/md.0000000000018033

Suzuki-Inoue, K. (2019). Platelets and cancer-associated thrombosis: focusing on the platelet activation receptor CLEC-2 and podoplanin. Blood 134, 1912-1918. doi: 10.1182/blood.20190 01388

Sylman, J. L., Mitrugno, A., Tormoen, G. W., Wagner, T. H., Mallick, P., and McCarty, O. J. T. (2017). Platelet count as a predictor of metastasis and venous thromboembolism in patients with cancer. Converg Sci. Phys. Oncol. 3:023001. doi: 10.1088/2057-1739/aa6c05

Takagi, S., Tsukamoto, S., Park, J., Johnson, K. E., Kawano, Y., Moschetta, M., et al. (2018). Platelets enhance multiple myeloma progression via IL-1 $\beta$ upregulation. Clin. Cancer Res. 24, 2430-2439. doi: 10.1158/1078-0432.Ccr-17-2003

Takemoto, A., Miyata, K., and Fujita, N. (2017). Platelet-activating factor podoplanin: from discovery to drug development. Cancer Metastasis Rev. 36, 225-234. doi: 10.1007/s10555-017-9672-9672

Tang, M., Jiang, L., Lin, Y., Wu, X., Wang, K., He, Q., et al. (2017). Platelet microparticle-mediated transfer of miR-939 to epithelial ovarian cancer cells promotes epithelial to mesenchymal transition. Oncotarget 8, 97464-97475. doi: 10.18632/oncotarget.22136

Tesselaar, M. E., Romijn, F. P., Van Der Linden, I. K., Prins, F. A., Bertina, R. M., and Osanto, S. (2007). Microparticle-associated tissue factor activity: a link between cancer and thrombosis? J. Thromb Haemost 5, 520-527. doi: 10.1111/ j.1538-7836.2007.02369.x

Thaler, J., Ay, C., Mackman, N., Bertina, R. M., Kaider, A., Marosi, C., et al. (2012). Microparticle-associated tissue factor activity, venous thromboembolism and mortality in pancreatic, gastric, colorectal and brain cancer patients. J. Thromb. Haemost. 10, 1363-1370. doi: 10.1111/j.1538-7836.2012.04754.x

Tilley, R. E., Holscher, T., Belani, R., Nieva, J., and Mackman, N. (2008). Tissue factor activity is increased in a combined platelet and microparticle sample from cancer patients. Thromb Res. 122, 604-609. doi: 10.1016/j.thromres.2007. 12.023

Tjomsland, V., Pomianowska, E., Aasrum, M., Sandnes, D., Verbeke, C. S., and Gladhaug, I. P. (2016). Profile of MMP and TIMP expression in human pancreatic stellate cells: regulation by IL-1 $\alpha$ and TGF $\beta$ and implications for migration of pancreatic Cancer Cells. Neoplasia 18, 447-456. doi: 10.1016/j.neo. 2016.06.003

Tomaiuolo, M., Brass, L. F., and Stalker, T. J. (2017). Regulation of platelet activation and coagulation and its role in vascular injury and arterial thrombosis. Interv. Cardiol. Clin. 6, 1-12. doi: 10.1016/j.iccl.2016.08.001

Toth, B., Liebhardt, S., Steinig, K., Ditsch, N., Rank, A., Bauerfeind, I., et al. (2008). Platelet-derived microparticles and coagulation activation in breast cancer patients. Thromb Haemost 100, 663-669.

Trajkovic-Arsic, M., Kalideris, E., and Siveke, J. T. (2013). The role of insulin and IGF system in pancreatic cancer. J. Mol. Endocrinol. 50, R67-R74. doi: 10.1530/jme-12-0259

Tsai, S., McOlash, L., Palen, K., Johnson, B., Duris, C., Yang, Q., et al. (2018). Development of primary human pancreatic cancer organoids, matched stromal and immune cells and 3D tumor microenvironment models. BMC Cancer 18:335. doi: 10.1186/s12885-018-4238-4234

Tutt, A. N. J., Garber, J. E., Kaufman, B., Viale, G., Fumagalli, D., Rastogi, P., et al. (2021). Adjuvant Olaparib for Patients with BRCA1- or BRCA2-Mutated Breast Cancer. N. Engl. J. Med. 384, 2394-2405. doi: 10.1056/NEJMoa2105215

Tzanakakis, G. N., Agarwal, K. C., and Vezeridis, M. P. (1993). Prevention of human pancreatic cancer cell-induced hepatic metastasis in nude mice by dipyridamole and its analog RA-233. Cancer 71, 2466-2471.

van der Zee, P. M., Biró, E., Ko, Y., de Winter, R. J., Hack, C. E., Sturk, A., et al. (2006). P-selectin- and CD63-exposing platelet microparticles reflect platelet activation in peripheral arterial disease and myocardial infarction. Clin. Chem. 52, 657-664. doi: 10.1373/clinchem.2005.057414

van Roessel, S., Kasumova, G. G., Verheij, J., Najarian, R. M., Maggino, L., de Pastena, M., et al. (2018). International validation of the eighth edition of the american joint committee on Cancer (AJCC) TNM staging system in patients with resected pancreatic Cancer. JAMA Surg. 153:e183617. doi: 10. 1001/jamasurg.2018.3617

Visentin, B., Vekich, J. A., Sibbald, B. J., Cavalli, A. L., Moreno, K. M., Matteo, R. G., et al. (2006). Validation of an anti-sphingosine-1-phosphate antibody as a potential therapeutic in reducing growth, invasion, and angiogenesis in multiple tumor lineages. Cancer Cell 9, 225-238. doi: 10.1016/j.ccr.2006.02.023

Walsh, T. G., Metharom, P., and Berndt, M. C. (2015). The functional role of platelets in the regulation of angiogenesis. Platelets 26, 199-211. doi: 10.3109/ 09537104.2014 .909022 
Wang, C. S., Wu, T. L., Tsao, K. C., and Sun, C. F. (2006). Serum TIMP-1 in gastric cancer patients: a potential prognostic biomarker. Ann. Clin. Lab. Sci. 36, 23-30.

Wang, J. G., Geddings, J. E., Aleman, M. M., Cardenas, J. C., Chantrathammachart, P., Williams, J. C., et al. (2012). Tumor-derived tissue factor activates coagulation and enhances thrombosis in a mouse xenograft model of human pancreatic cancer. Blood 119, 5543-5552. doi: 10.1182/blood-2012-01-402156

Wang, J. P., Wu, C. Y., Yeh, Y. C., Shyr, Y. M., Wu, Y. Y., Kuo, C. Y., et al. (2015). Erlotinib is effective in pancreatic cancer with epidermal growth factor receptor mutations: a randomized, open-label, prospective trial. Oncotarget 6, 18162-18173. doi: $10.18632 /$ oncotarget. 4216

Wang, Y., Sun, Y., Li, D., Zhang, L., Wang, K., Zuo, Y., et al. (2013). Platelet P2Y12 is involved in murine pulmonary metastasis. PLoS One 8:e80780. doi: 10.1371/journal.pone. 0080780

Welsh, J. D., Stalker, T. J., Voronov, R., Muthard, R. W., Tomaiuolo, M., Diamond, S. L., et al. (2014). A systems approach to hemostasis: 1. the interdependence of thrombus architecture and agonist movements in the gaps between platelets. Blood 124, 1808-1815. doi: 10.1182/blood-2014-01-550335

Westphalen, C. B., and Olive, K. P. (2012). Genetically engineered mouse models of pancreatic cancer. Cancer J. 18, 502-510. doi: 10.1097/PPO.0b013e31827ab4c4

Xiang, T., Xia, X., and Yan, W. (2017). Expression of matrix Metalloproteinases-2/9 is associated with microvessel density in pancreatic Cancer. Am. J. Ther. 24, e431-e434. doi: 10.1097/mjt.0000000000000424

Xiao, G. G. (2020). Targeting serotonin system in pancreatic Cancer. Pancreas 49:e1. doi: $10.1097 / \mathrm{mpa} .0000000000001417$

Xue, L., Xie, L., Song, X., and Song, X. (2018). Identification of potential tumoreducated platelets RNA biomarkers in non-small-cell lung cancer by integrated bioinformatical analysis. J. Clin. Lab. Anal. 32:e22450. doi: 10.1002/jcla.22450

Yagyu, T., Saito, H., Sakamoto, T., Uchinaka, E., Morimoto, M., Hanaki, T., et al. (2021). Decreased mean platelet volume predicts poor prognosis in patients with pancreatic cancer. BMC Surg. 21:8. doi: 10.1186/s12893-020-00976-975

Yang, Y., Stang, A., Schweickert, P. G., Lanman, N. A., Paul, E. N., Monia, B. P., et al. (2019). Thrombin signaling promotes pancreatic adenocarcinoma through PAR-1-Dependent immune evasion. Cancer Res. 79, 3417-3430. doi: 10.1158/0008-5472.Can-18-3206

Yenigürbüz, F. D., Kızmazoğlu, D., Ateş, H., Erdem, M., Tüfekçi, Ö, Yılmaz, Ş, et al. (2019). Analysis of apoptotic, platelet-derived, endothelial-derived, and tissue factor-positive microparticles of children with acute lymphoblastic leukemia during induction therapy. Blood Coagul. Fibrinolysis 30, 149-155. doi: 10.1097/ mbc. 0000000000000811

Yin, J. B., Li, N., Cui, M. M., Wang, X., and Wang, R. T. (2020). Reduced mean platelet volume levels predict shorter survival in patients with resectable pancreatic ductal adenocarcinoma and type 2 diabetes. BMC Gastroenterol. 20:143. doi: 10.1186/s12876-020-01225-y

Yin, J. B., Wang, X., Zhang, X., Liu, L., and Wang, R. T. (2018). Mean platelet volume predicts survival in pancreatic cancer patients with synchronous liver metastases. Sci. Rep. 8:6014. doi: 10.1038/s41598-018-24539-24530
Yoshikawa, K., Tanabe, E., Shibata, A., Inoue, S., Kitayoshi, M., Okimoto, S., et al. (2013). Involvement of oncogenic K-ras on cell migration stimulated by lysophosphatidic acid receptor-2 in pancreatic cancer cells. Exp. Cell Res. 319, 105-112. doi: 10.1016/j.yexcr.2012.09.014

Yu, J., Ding, Z., Yang, Y., and Liu, S. (2018). Increased platelet-to-lymphocytes ratio is associated with poor long-term prognosis in patients with pancreatic cancer after surgery. Medicine (Baltimore) 97:e11002. doi: 10.1097/md. 0000000000011002

Yu, L. X., Yan, L., Yang, W., Wu, F. Q., Ling, Y., Chen, S. Z., et al. (2014). Platelets promote tumour metastasis via interaction between TLR4 and tumour cellreleased high-mobility group box1 protein. Nat. Commun. 5:5256. doi: 10.1038/ ncomms6256

Yu, M., Li, T., Li, B., Liu, Y., Wang, L., Zhang, J., et al. (2020). Phosphatidylserineexposing blood cells, microparticles and neutrophil extracellular traps increase procoagulant activity in patients with pancreatic cancer. Thromb Res. 188, 5-16. doi: 10.1016/j.thromres.2020.01.025

Yuzawa, S., Kano, M. R., Einama, T., and Nishihara, H. (2012). PDGFR $\beta$ expression in tumor stroma of pancreatic adenocarcinoma as a reliable prognostic marker. Med. Oncol. 29, 2824-2830. doi: 10.1007/s12032-012-0193-190

Zhang, H., Jiang, P., Zhang, C., Lee, S., Wang, W., and Zou, H. (2018). PAR4 overexpression promotes colorectal cancer cell proliferation and migration. Oncol. Lett. 16, 5745-5752. doi: 10.3892/ol.2018. 9407

Zhang, K., Gao, H. F., Mo, M., Wu, C. J., Hua, Y. Q., Chen, Z., et al. (2019). A novel scoring system based on hemostatic parameters predicts the prognosis of patients with advanced pancreatic cancer. Pancreatology 19, 346-351. doi: 10.1016/j.pan.2018.12.010

Zhou, G. X., Ding, X. L., Wu, S. B., Zhang, H. F., Cao, W., Qu, L. S., et al. (2015). Inhibition of 5-lipoxygenase triggers apoptosis in pancreatic cancer cells. Oncol. Rep. 33, 661-668. doi: 10.3892/or.2014.3650

Conflict of Interest: The authors declare that the research was conducted in the absence of any commercial or financial relationships that could be construed as a potential conflict of interest.

Publisher's Note: All claims expressed in this article are solely those of the authors and do not necessarily represent those of their affiliated organizations, or those of the publisher, the editors and the reviewers. Any product that may be evaluated in this article, or claim that may be made by its manufacturer, is not guaranteed or endorsed by the publisher.

Copyright () 2021 Mai and Inkielewicz-Stepniak. This is an open-access article distributed under the terms of the Creative Commons Attribution License (CC BY). The use, distribution or reproduction in other forums is permitted, provided the original author(s) and the copyright owner(s) are credited and that the original publication in this journal is cited, in accordance with accepted academic practice. No use, distribution or reproduction is permitted which does not comply with these terms. 